\title{
Efficacy and safety of intracervical Foley's in women receiving sublingual misoprostol for induction of labour: a randomized controlled trial
}

\section{Salini Yadaraju*, Latha Chaturvedula, Sasirekha Rengaraj}

\begin{abstract}
Department of Obstetrics and Gynaecology, Jawaharlal Institute of Post graduate Medical Education and Research, Pondicherry, Puducherry, India
\end{abstract}

Received: 26 July 2020

Accepted: 04 September 2020

\author{
*Correspondence: \\ Dr. Salini Yadaraju, \\ E-mail: salini.ysn@gmail.com
}

Copyright: (C) the author(s), publisher and licensee Medip Academy. This is an open-access article distributed under the terms of the Creative Commons Attribution Non-Commercial License, which permits unrestricted non-commercial use, distribution, and reproduction in any medium, provided the original work is properly cited.

\begin{abstract}
Background: Induction of labour can be carried out by medical or mechanical methods, used alone or in combination. This study is to evaluate the efficacy and safety of intracervical Foley's in women receiving sublingual misoprostol for induction of labour.

Methods: We randomized 230 primi gravidae at $\geq 37$ weeks of gestation, with singleton pregnancy, cephalic presentation requiring induction, with Bishop score $\leq 4$ using block randomization into study and control groups. Both groups received $50 \mu \mathrm{g}$ sublingual misoprostol every fourth hourly till active labour was achieved or upto a maximum of 6 doses. The study group was induced simultaneously with intracervical Foley catheter.

Results: Mean induction to labour interval in study and control groups was $11.191 \pm 7.14$ hours and $11.758 \pm 6.26$ hours while mean induction to delivery interval was $17.502 \pm 7.93$ hours and 18.275 \pm 7.66 hours respectively with no significant difference between the groups $(\mathrm{p}=0.522$ and 0.453$)$. More women in study group than in the control $(51.3 \%$ versus $33.9 \%)$ were in active labour within ten hours of induction $(\mathrm{p}=0.001)$. Caesarean section rate was $23.5 \%$ and $19.1 \%$ in study and control groups $(\mathrm{p}=0.497)$, the most common indication being foetal distress. Secondary outcomes like foetal heart rate abnormalities, oxytocin requirement were comparable between the two groups. APGAR scores and NICU admission rate were similar in both groups. There was no significant maternal or neonatal morbidity.

Conclusions: Though there was no significant reduction in induction to labour or delivery interval with synchronous use of sublingual misoprostol and Foley's, there was no increase in the complications encountered.
\end{abstract}

Keywords: Induction of labour, Intracervical Foley’s, Misoprostol, Sublingual

\section{INTRODUCTION}

The concept of induction of labour has arisen mainly because of the need to interrupt the wait for spontaneous onset of labour owing to a number of maternal or foetal indications that warrant termination of pregnancy.

WHO (World Health Organization) global survey that included 24 countries and more than 3,00,000 deliveries concluded that $9.6 \%$ of those deliveries needed induction of labour. ${ }^{1}$ In Asia, a secondary analysis of WHO global survey on maternal and neonatal health has shown that $12.1 \%$ of deliveries were induced. ${ }^{2}$ The indications for induction of labour can be varied and so can be the methods used for induction. Medical methods for induction of labour include oxytocin, prostaglandins, nitric oxide donors, oestradiol gel. Mechanical methods include stripping of membranes, introduction of mechanical dilators like intra cervical Foley catheter and hygroscopic dilators. 
Medical methods usually act by stimulating myometrial contractions while mechanical methods soften the cervix. WHO approves the usage of low dose, $25 \mu \mathrm{g}$ oral misoprostol every second hourly or low dose vaginal misoprostol, sixth hourly. ${ }^{1}$ Studies over the years have explored the various routes and dosages of misoprostol that can be safely used for the induction of labour. ${ }^{3,4}$ As a mechanical method, Foley's catheter placed intracervically, just above the internal os and tied with traction is found to improve Bishop score satisfactorily and is recommended by various bodies. ${ }^{1,5}$ Usage of mechanical methods along with a medical method has shown to improve the induction-delivery interval and perinatal outcome. ${ }^{6,7}$

Since sublingual misoprostol has an added advantage of ease of administration, our study has been conducted using Foley catheter with concurrent administration of sublingual misoprostol, compared with sublingual misoprostol alone in terms of induction to labour and delivery interval, maternal and perinatal outcome.

\section{METHODS}

This was a prospective randomized controlled trial conducted in the Department of Obstetrics and Gynaecology, Jawaharlal Institute of Post Graduate Medical Education and Research, a tertiary level teaching hospital from December 2015 to May 2017.

\section{Inclusion criteria}

Primi gravidae at 37 weeks of gestation or more, aged 18 years or more, with singleton pregnancy and vertex presentation, who needed induction of labour, with Bishop score less than or equal to four were included as study participants.

\section{Exclusion criteria}

Women with premature rupture of membranes, placenta praevia, abruption, previously scarred uterus (myomectomy/ septal resection), those for trial of labour, those with fetuses diagnosed with congenital anomalies, allergy to prostaglandins and with oligohydramnios (AFI $<5 \mathrm{~cm}$ ) were excluded.

Women who satisfied the criteria were included in the study after obtaining informed consent. They were randomized into two groups, namely study and control group sequentially, based on computer generated randomization sequence using opaque envelopes prepared by an uninvolved third party before the start of the study.

In study group, 22F Foley's was introduced intracervically under aseptic precautions such that the bulb of the catheter lies over the internal os and inflated with $60 \mathrm{ml}$ of distilled water. Concurrently $50 \mu \mathrm{g}$ of sublingual misoprostol was given, every fourth hourly upto a maximum of 6 doses. Sublingual misoprostol alone $(50 \mu \mathrm{g})$ was given, every fourth hourly upto a maximum of 6 doses to women belonging to control group. The administration of next dose of misoprostol was decided based upon the frequency and intensity of uterine contractions. Vaginal examination was performed as and when required or on expulsion of Foley. At any time during the study, depending upon the discretion of the medical professional in charge, either artificial rupture of membranes or oxytocin augmentation was started as per the dosage protocol followed in our institution regularly.

The data so obtained was analysed using software SPSS 18.0 and $\mathrm{R}$ environment ver.3.2.2. The labour outcome measures were induction to labour and induction to delivery interval, foetal heart rate abnormalities, number of doses of misoprostol used, additional usage of inducing agents. The mode of delivery and any maternal complications that occurred intrapartum or postpartum were noted. APGAR score at 1 and 5 minutes, type of liquor, meconium aspiration, birth asphyxia, respiratory distress syndrome NICU admission, duration of stay in NICU and neonatal mortality were studied as perinatal outcome measures.

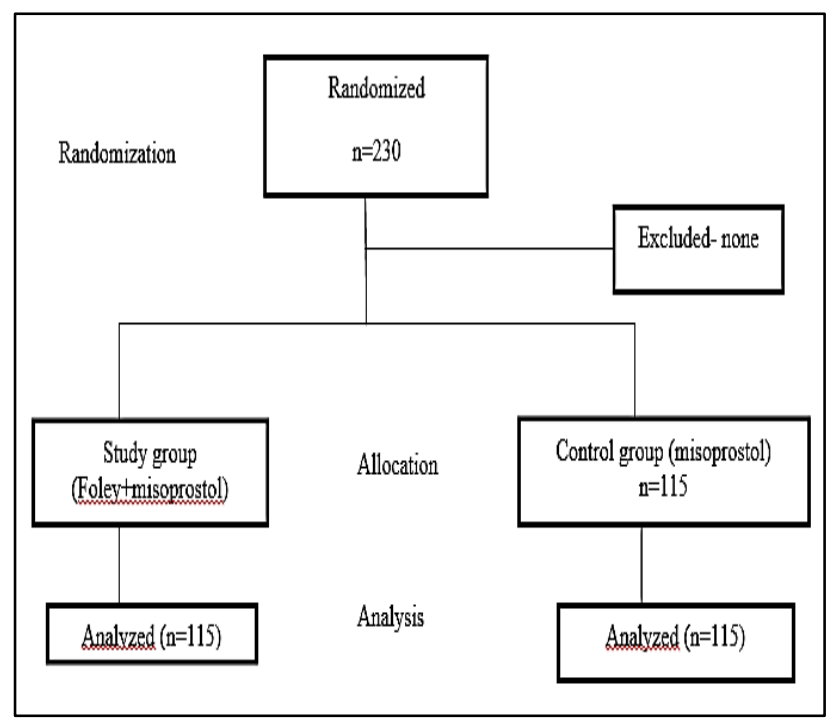

Figure 1: Consort flow diagram for participants involved in the trial.

\section{RESULTS}

A total of 230 women satisfying the inclusion criteria were enrolled into the study during the period from December 2015 to May 2017.

There was no significant difference between the two groups in terms of baseline characteristics like age, gestational age at induction, indications for induction, amniotic fluid index and number of doses of misoprostol used (Table 1). As many as $28.7 \%$ women of the total were more than 41 weeks of gestation. When pre- 
induction Bishop score was compared, it was found that a higher proportion of women belonged to lesser Bishop's score in study group when compared to control group. Majority of the women had multiple indications for induction simultaneously. Nearly $70 \%$ of the women induced were post-dated. Twelve percentage of the women were diabetic, either gestational diabetes or type 2 diabetes mellitus. Hypertensive disorders of pregnancy were found in $31.7 \%$ of all the women that were induced. All the 16 women with $\mathrm{Rh}$ incompatible pregnancies were post-dated.

Table 1: Demographic characteristics of participants.

\begin{tabular}{|c|c|c|c|}
\hline Characteristic & $\begin{array}{l}\text { Study } \\
\text { group } \\
\mathbf{N}(\%)\end{array}$ & $\begin{array}{l}\text { Control } \\
\text { group } \\
\mathbf{N}(\%)\end{array}$ & $\begin{array}{l}\text { P- } \\
\text { value }\end{array}$ \\
\hline Age in years & $24.02 \pm 3.07$ & $24.43 \pm 2.76$ & 0.290 \\
\hline \multicolumn{4}{|c|}{ Gestational age in weeks } \\
\hline $37-38 \pm 6$ & $15(13)$ & $13(11.3)$ & \multirow{4}{*}{0.588} \\
\hline $39-39 \pm 6$ & $12(10.4)$ & $18(15.7)$ & \\
\hline $40-40 \pm 6$ & $52(45.2)$ & $54(47)$ & \\
\hline$\geq 41$ weeks & $36(31.3)$ & $30(26.1)$ & \\
\hline \multicolumn{4}{|l|}{ Bishop score } \\
\hline 1 & $0(0)$ & $1(0.9)$ & \multirow{4}{*}{0.03} \\
\hline 2 & $27(23.5)$ & $11(9.6)$ & \\
\hline 3 & $42(36.5)$ & $35(30.4)$ & \\
\hline 4 & $46(40)$ & $68(59.1)$ & \\
\hline \multicolumn{4}{|l|}{ AFI } \\
\hline$>8 \mathrm{~cm}$ & $77(67)$ & $85(73.9)$ & \multirow{2}{*}{0.248} \\
\hline $5-8 \mathrm{~cm}$ & $38(33)$ & $30(26.1)$ & \\
\hline \multicolumn{4}{|c|}{ Indications for induction } \\
\hline Past dates & 83 & 77 & \\
\hline Decreased liquor & 38 & 30 & \\
\hline Hypertension & 35 & 38 & \\
\hline Diabetes & 9 & 19 & \\
\hline Rh incompatibility & 6 & 10 & \\
\hline $\begin{array}{l}\text { Decreased foetal } \\
\text { movements }\end{array}$ & 2 & 0 & \\
\hline \multicolumn{4}{|c|}{ No of doses of PGE1 } \\
\hline$\leq 3$ & 94 & 81 & \multirow{2}{*}{0.04} \\
\hline$>3$ & 21 & 34 & \\
\hline
\end{tabular}

Table 2: Primary outcomes.

\begin{tabular}{|llll|}
\hline Characteristic & $\begin{array}{l}\text { Study } \\
(\mathbf{n = 1 1 5})\end{array}$ & $\begin{array}{l}\text { Control } \\
(\mathbf{n}=115)\end{array}$ & P value \\
\hline $\begin{array}{l}\text { Mean induction } \\
\text { to labour } \\
\text { interval }\end{array}$ & $\begin{array}{l}11.191 \pm 7.14 \\
\text { hours }\end{array}$ & $\begin{array}{l}11.758 \pm 6.26 \\
\text { hours }\end{array}$ & 0.522 \\
\hline $\begin{array}{l}\text { Induction to } \\
\text { labour interval } \\
<\mathbf{6 0 0} \text { minutes }\end{array}$ & $59(51.3 \%)$ & $39(33.9 \%)$ & 0.001 \\
\hline $\begin{array}{l}\text { Mean induction } \\
\text { to delivery } \\
\text { interval }\end{array}$ & $\begin{array}{l}17.502 \pm 7.93 \\
\text { hours }\end{array}$ & $\begin{array}{l}18.275 \pm 7.66 \\
\text { hours }\end{array}$ & 0.453 \\
\hline
\end{tabular}

When primary outcomes were compared (Table 2), mean induction to labour interval in control and study groups was $705.52 \pm 375.84$ minutes and $671.48 \pm 428.42$ minutes respectively with no significant difference between the two groups $(\mathrm{p}=0.522)$. In the study group, $51.3 \%$ women entered active labour within ten hours of induction while only $33.9 \%$ were in labour in the control group in the same time period. The difference between the two groups was statistically significant $(\mathrm{p}=0.001)$. The mean interval between induction and delivery in control and study groups was 18.275 \pm 7.66 hours and 17.502 \pm 7.93 hours respectively with no statistically significant difference (Table 2).

Table 3: Secondary outcomes.

\begin{tabular}{|c|c|c|c|}
\hline Characteristic & $\begin{array}{l}\text { Study } \\
(\mathbf{n}=\mathbf{1 1 5}) \\
\mathbf{N}(\%)\end{array}$ & $\begin{array}{l}\text { Control } \\
(\mathbf{n}=115) \\
\mathbf{N}(\%)\end{array}$ & P value \\
\hline $\begin{array}{l}\text { Presence of FHR } \\
\text { abnormalities }\end{array}$ & $45(39.1)$ & $47(40.9)$ & 0.788 \\
\hline Colour of liquor & & & \\
\hline Clear & $71(61.7)$ & $67(58.3)$ & \multirow{3}{*}{0.686} \\
\hline $\begin{array}{l}\text { MSL (meconium } \\
\text { stained liquor) }\end{array}$ & $44(38.3)$ & $47(40.9)$ & \\
\hline $\begin{array}{l}\text { Blood stained } \\
\text { liquor }\end{array}$ & $0(0)$ & $1(0.9)$ & \\
\hline $\begin{array}{l}\text { Requirement of } \\
\text { oxytocin }\end{array}$ & $74(64.3)$ & $73(63.5)$ & 0.891 \\
\hline $\begin{array}{l}\text { No. of caesarean } \\
\text { deliveries }\end{array}$ & 27 (23.5) & $22(19.1)$ & 0.426 \\
\hline $\begin{array}{l}\text { No. of } \\
\text { instrumental } \\
\text { deliveries }\end{array}$ & 31 & 25 & \\
\hline $\begin{array}{l}\text { Maternal } \\
\text { complications }\end{array}$ & 7 & 5 & 0.203 \\
\hline \multicolumn{4}{|l|}{ APGAR score 1' } \\
\hline$<5$ & $5(4.3)$ & $5(4.3)$ & \multirow{2}{*}{1.000} \\
\hline$>5$ & $110(95.7)$ & $110(95.7)$ & \\
\hline \multicolumn{3}{|l|}{ APGAR score 5' } & \multirow{2}{*}{0.155} \\
\hline$<5$ & $2(1.7)$ & $0(0)$ & \\
\hline $\begin{array}{l}\text { NICU } \\
\text { admissions }\end{array}$ & 20 & 16 & \\
\hline \multicolumn{3}{|l|}{ NICU admissions } & \multirow{5}{*}{0.654} \\
\hline RDS & $13(11.3)$ & $12(10.4)$ & \\
\hline Birth asphyxia & $4(3.5)$ & $4(3.5)$ & \\
\hline NNJ & $1(0.9)$ & $0(0)$ & \\
\hline Others & $2(1.7)$ & $0(0)$ & \\
\hline
\end{tabular}

Secondary outcomes like foetal heart rate abnormalities, colour of liquor, requirement of oxytocin were comparable between the two groups (Table 3). Caesarean section rate was slightly higher in the study group $(23.5 \%)$ than control group $(19.1 \%)$ but not statistically significant. Instrumental vaginal delivery was necessitated in $24 \%$ of the women for various indications including non reassuring foetal heart rate, for prolonged second stage of labour or to cut short second stage.

Maternal complications encountered were postpartum haemorrhage (1), hyperstimulation (3), febrile morbidity (6) and complete perineal tear (2) with no significant 
difference between study and control groups $(\mathrm{p}=0.203)$. No serious morbidity or mortality was seen. Neonatal complications that required intensive care unit admission included birth asphyxia, respiratory distress and neonatal jaundice.

\section{DISCUSSION}

Our study was carried out in 230 subjects and it was found out that there was no significant difference between the two groups with respect to either induction to labour or to delivery interval. The shortening was found to be only 30 minutes and 45 minutes on an average, between the groups from induction to labour and to delivery but the number of women who were in active labour within ten hours of induction was significantly higher in the study group.

Population characteristics like age distribution of the subjects, gestational age at induction were comparable to other similar studies. ${ }^{8-10}$ In the study by Hill, in which oral misoprostol with Foley's was used, the pre induction Bishop score was lower than our study (3 versus 4$){ }^{9}$

In the study by Carbone et al where vaginal misoprostol was used, the mean induction to delivery interval was $15.3 \pm 6.5$ hours $(918 \pm 390 \mathrm{~min})$ and $18.3 \pm 8.7$ hours $(1098 \pm 522 \mathrm{~min})$ in the study and control groups respectively. ${ }^{8}$ Even in a study by Hill, where oral misoprostol was used, induction to delivery interval was shorter in the combination group (12.9 hours versus 17.8 hours).$^{9}$ In these two studies, the difference in induction to delivery intervals was significant. In our study the combination had resulted in a shorter induction to labour as well as delivery interval. It was not significantly different probably due to the higher pre induction Bishop score in the control group that resulted in shorter induction to labour as well as delivery interval in the control group that reflected as non-significant difference between the two groups.

More than half of the women had spontaneous vaginal delivery in our study $(54.3 \%)$. The proportion of women who delivered vaginally was $80 \%$ in the control group and $76.5 \%$ in the study group similar to other studies using vaginal misoprostol. ${ }^{8}$ These results were also similar to the studies conducted by Carbone et al and Aduloju et al with respect to difference between the two groups but the rate of caesarean sections was found to be slightly lower in our study when compared to the others probably due to the greater sample size. ${ }^{8,10}$ Oxytocin requirement was similar in both the groups in our study which concurred with the findings of the study by Hill et al. ${ }^{9}$ This is contrary to the study conducted by Aduloju et al in which the oxytocin requirement was significantly lower in the combination group (31.4\% versus $61.4 \%) .{ }^{10}$

Concurrent to study findings of Hill, the most frequent indication for operative delivery was non reassuring foetal status. ${ }^{9}$ Meconium stained liquor as a complication of induction of labour was found in $40.9 \%$ and $38.3 \%$ of the women in control and study groups. The proportion was very high when compared to other studies probably because of the higher number of postdated pregnancies in our study. The incidence of meconium stained liquor ranged over $2 \%$ to $24 \%$ in other similar studies using different routes of misoprostol. ${ }^{8-10}$

The incidence of chorioamnionitis in two similar studies that used vaginal misoprostol and found to be $10.2 \%$ and $4.74 \%$ respectively which was much higher than our study $(0 \%) .{ }^{8,9}$ This can be attributed to the fact that route of administration of misoprostol being sublingual in our study, had avoided multiple vaginal examinations that could have resulted in lesser incidence of febrile morbidity which can be described as an added advantage of sublingual misoprostol.

Fifteen percent (36) of the babies born (20 and 16 from study and control group respectively) were admitted to NICU. Birth asphyxia was suspected in a total of eight babies $(3.47 \%)$, four from each group. Higher incidence was found in the study by Aduloju et al $(6.6 \%)$ using low dose vaginal misoprostol with Foley. ${ }^{10}$ In conclusion, there was no serious maternal or neonatal morbidity in our study.

Our study has shown that simultaneous usage of misoprostol with Foley's has not significantly shortened the induction-labour or induction-delivery interval. Moreover, studies done using low dose vaginal misoprostol by Carbone et al, Aduloju et al and Ugwueven et al though have shown to shorten the induction-labour interval and induction-delivery interval, may have had favourable results due to inclusion of multiparous women. ${ }^{8,10,11}$ Our study included only primigravidae who may be inherently slower to respond to labour inducing agents.

\section{CONCLUSION}

In conclusion, though no statistically significant reduction in induction to labour or delivery was seen with synchronous use of sublingual misoprostol and Foley's, there was no increase in the complications encountered. Hence we suggest the conduct of further similar trials in a much larger population as it may have a positive impact in shortening of labour duration which may in turn decrease the duration of hospital stay and its associated negative implications.

\section{ACKNOWLEDGMENTS}

Authors acknowledge the help provided by the residents and labour room staff for the smooth conduct of the study. The authors would also like to thank the patients who have consented and participated in the study.

\author{
Funding: No funding sources \\ Conflict of interest: None declared \\ Ethical approval: The study was approved by the \\ Institutional Ethics Committee
}




\section{REFERENCES}

1. WHO Recommendations for Induction of Labour. Geneva: World Health Organization; 2011. Available at: http://www.ncbi.nlm.nih.gov/books/ NBK131963/. Accessed on 14 March 2015.

2. ACOG Practice Bulletin No. 107: Induction of labor. Obstet Gynecol. 2009;114(2 Pt 1):386-97.

3. Vogel JP, Souza JP, Gülmezoglu AM. Patterns and outcomes of induction of labour in Africa and Asia: a secondary analysis of the WHO global survey on maternal and neonatal health. PLoS One. 2013;8(6):e65612.

4. Stock SJ, Ferguson E, Duffy A, Ford I, Chalmers J, Norman JE. Outcomes of elective induction of labour compared with expectant management: population based study. BMJ. 2012;344:e2838.

5. Davey MA, King J. Caesarean section following induction of labour in uncomplicated first births- a population-based cross-sectional analysis of 42,950 births. BMC Pregnancy Childbirth. 2016;16:92.

6. Gupta S, Shekhavath U, Premlata M, Madhu M. To study the fetomaternal outcome and progress of labour among induced versus spontaneous labour in nulliparous women (Using WHO partograph). Sch J App Med Sci. 2014;2(5A):1577-80.

7. Kaul B, Vallejo MC, Ramanathan S, Mandell G, Phelps AL, Daftary AR. Induction of labor with oxytocin increases cesarean section rate as compared with oxytocin for augmentation of spontaneous labor in nulliparous parturients controlled for lumbar epidural analgesia. J Clin Anesth. 2004;16(6):411-4.

8. Carbone JF, Tuuli MG, Fogertey PJ, Roehl KA, Macones GA. Combination of Foley bulb and vaginal misoprostol compared with vaginal misoprostol alone for cervical ripening and labor induction: a randomized controlled trial. Obstet Gynecol. 2013;121(2 Pt 1):247-52.

9. Hill JB, Thigpen BD, Bofill JA, Magann E, Moore LE, Martin JN. A randomized clinical trial comparing vaginal misoprostol versus cervical Foley plus oral misoprostol for cervical ripening and labor induction. Am J Perinatol. 2009;26(1):33-8.

10. Aduloju OP, Akintayo AA, Adanikin AI, Ade-ojo IP. Combined Foley's catheter with vaginal misoprostol for pre-induction cervical ripening: A randomised controlled trial. Aust N Z J Obstet Gynaecol. 2016;56(6):578-84.

11. Ugwu EO, Obi SN, Iferikigwe ES, Dim CC, Ezugwu FO. Membrane stripping to prevent post-term pregnancy in Enugu, Nigeria: a randomized controlled trial. Arch Gynecol Obstet. 2014;289(1):29-34.

Cite this article as: Yadaraju S, Chaturvedula L, Rengaraj S. Efficacy and safety of intracervical Foley's in women receiving sublingual misoprostol for induction of labour: a randomized controlled trial. Int J Reprod Contracept Obstet Gynecol 2020;9:4135-9. 